\title{
Da invisibilidade ao reconhecimento: a (im)posição das periferias nas lutas pela cidadania urbana
}

\author{
Fillipi Lúcio Nascimento ${ }^{1}$
}

\section{RESUMO}

A despeito dos discursos de "igualdade de direitos" e de "impessoalidade das leis” que intercalam a narrativa democrática brasileira, tradicionalmente, o exercício efetivo de uma cidadania urbana esteve vinculado a estritas noções de civilidade operadas em benefício de poucos e em detrimento de muitos. As periferias constituem um reflexo ambíguo desse processo. Ao mesmo tempo em que se apresentam como retratos das injustiças perpetradas contra os menos favorecidos, delas decorrem forças distintas (complementares ou excludentes) de contestação dessas injustiças, expressas na ressignificação do próprio sentido de exercício da cidadania, fazendo-a valer pelo uso da violência ou inscritas na apropriação e mobilização dos recursos políticos à disposição para subverter as lógicas de desigualdade em operação. Partindo do pressuposto de que os critérios de elucidação das categorias mobilizadas pelos distintos atores que integram a cena urbana brasileira informam a narrativa do ponto de vista daqueles que o ocupam o lugar de fala, neste artigo, articulamos conceitos da teoria sociológica dos conflitos em torno dos discursos dos "sujeitos periféricos" para refletirmos sobre as condições de exercício de uma cidadania citadina no Brasil.

Palavras-chave: Cidade; Cidadania; Conflitos urbanos; Periferias.

$\mathrm{M}$ aceió, 14 de setembro de 2018. Poderia ser mais uma tarde corriqueira de sexta-feira na praia de Ponta Verde se não fosse pela discussão que se

${ }^{1}$ Mestrando do Programa de Pós-Graduação em Sociologia da Universidade Federal de Alagoas. E-mail: fillipi.nascimento@hotmail.com. 
fazia ouvir desde a faixa de areia, a alguns metros da barraca onde estávamos. A nossa direita, ${ }^{2}$ um homem, branco, corpulento, em seus aparentes 50 anos de idade. Altivo, portava na mão esquerda um iPhone e na mão direita o dedo indicador em riste. À esquerda, uma mulher, negra, franzina, com nada mais que aparentes 30 anos. Não trazia consigo nenhum signo de posse. Possuía, contudo, indignação. Intransigente, com gritos e gestos ríspidos expressava claramente que não aceitaria a "repulsa" direcionada a ela e aos seus (o filho de poucos anos de idade que chorava desesperadamente no colo da tia, uma adolescente, que também a acompanhava, embora agora distante da cena). "Você nem devia estar aqui! Vá varrer uma casa ou qualquer outra coisa”, disse o homem desvencilhando-se de sua (aparente) esposa, que naquele momento entremeou-se na discussão para distanciá-lo dali. "A praia é sua? Quero saber se você comprou a praia? Cadê o documento dizendo que a praia é sua?”, respondeu-o a mulher com desdém. Não demorou muito para que os olhares (e celulares) dos que por ali passavam estivessem a postos captando a cena. Apercebendo-se do excesso de atenção que havia logrado ao expor sua "demanda", o homem passou a recolher seus pertences. "Eu não sou obrigado ouvir suas músicas, nem seus desaforos! Não sou obrigado a dividir a praia com gente ignorante como você", replicou. "Isso aqui é espaço público, não é particular não! Tá achando que é quem? É melhor ir embora mesmo!”, instigou-o a mulher em sua razão. A passos largos, o homem e sua esposa se retiraram da praia seguindo em direção a um dos apartamentos situados logo após a avenida que separa a faixa residencial da faixa de praia. Tomando o filho nos braços e fazendo-o se acalmar, a mulher voltou a se sentar na cadeira alugada sob o guarda-sol, religando seu aparelho de som.

${ }^{2}$ Somente ao transcrevermos esse episódio nos damos conta da estranha ironia da associação entre a posição física dos atores em relação a nós e a projeção da posição política desses atores a partir de suas distintas condutas. 
Esse episódio ilustra um aspecto sensível das diversas contradições que marcam o convívio urbano no Brasil. Referimo-nos às disputas pelo efetivo exercício de cidadanias que têm a cidade como principal objeto de reivindicação. A despeito dos discursos de "igualdade de direitos" e de "impessoalidade das leis" que intercalam a narrativa democrática brasileira, tradicionalmente, o exercício dessas cidadanias urbanas esteve restrito a noções de civilidade operadas em benefício de alguns segmentos sociais em detrimento de outros. A busca pelo reconhecimento político que justifica e que é produzido a partir dos usos e contra-usos do espaço público (leia-se "a cidade") é, no Brasil, historicamente condicionada por códigos de conduta que sustentam a civilidade como prerrogativa para a manutenção de privilégios e, portanto, de desigualdades (LEITE, 2004).

As periferias constituem um reflexo ambíguo desse processo: se por um lado elas se apresentam como retratos das injustiças perpetradas contra os menos favorecidos, por outro, delas emanam forças distintas (ora complementares, ora excludentes) de contestação dessas mesmas injustiças, expressas na ressignificação do próprio sentido do exercício da cidadania (fazendo-a valer pelo uso da violência) ou aplicadas no gerenciamento formal dos (poucos) recursos políticos à disposição para subverter as lógicas de desigualdade em operação.

Neste artigo procuramos refletir sobre as condições para a tomada de posição das periferias nos conflitos que decorrem da busca pelo exercício da cidadania urbana no Brasil. Revisamos entrevistas realizadas no curso de pesquisas distintas realizadas entre os anos de 2015 e 2017 em comunidades periféricas das cidades de Maceió (AL), de Belo Horizonte (MG) e do Rio de Janeiro (RJ). Ao reconhecermos que os critérios de elucidação das categorias mobilizadas informam a narrativa do ponto de vista daquele que o ocupa o lugar de fala, articulamos conceitos da teoria sociológica dos conflitos em torno dos discursos dos "sujeitos periféricos" 
a fim de compreendermos as circunstâncias que os motivam a desenvolver estratégias e a operacionalizá-las na insurgência contra os esquemas de reforço impostos por outros atores que integram a cena urbana brasileira.

$\mathrm{O}$ artigo encontra-se divido em outras quatro seções para além desta introdução: na primeira seção descrevemos sinteticamente as contradições estruturais do processo de redemocratização e suas repercussões sobre a atual conjuntura brasileira (com ênfase sobre as questões relativas aos conflitos urbanos). Na segunda seção apresentamos as notas metodológicas deste estudo e tecemos breves observações em torno dos lugares de fala do pesquisador e dos sujeitos-objeto pesquisados. A terceira seção é reservada para uma análise das falas selecionadas visando a apreensão dos efeitos do processo histórico de privações sobre a dinâmica da vida nas periferias e seus reflexos na elaboração e no aparelhamento de estratégias de subversão. Por fim, reiteramos os principais argumentos mobilizados ao longo do texto e o encerramos com algumas considerações pontuais.

\section{As contradições estruturais da redemocratização brasileira}

Não é de se estranhar a grande adesão ao extremismo apregoado na campanha presidencial de 2018. O autoritarismo sempre se fez presente na história da nação. Suas raízes são tanto mais profundas que as práticas determinadas pelas ditaduras de 1937 e de 1964, e marcam a sociedade brasileira em um ciclo contínuo de dependência dos sistemas de desigualdades perpetrados pelas classes dominantes, reproduzindo-se regularmente pela violência indireta e ilegal do Estado.

O gradualismo, a lentidão e a influência exercida pelos antigos dirigentes autoritários (fundada em prerrogativas garantidas pela elite civil brasileira) reforçaram práticas políticas tradicionais que não apenas obstaculizaram o processo de redemocratização, mas também 
constrangeram (e ainda constrangem) a consolidação do novo regime no Brasil (MARQUES, 2018). Inaugurou-se uma democracia sustentando-se as mesmas condições de reprodução das hierarquias, dos privilégios, das desigualdades. Esse tipo de contradição denuncia o caráter estratégico e utilitário da adesão ao novo regime.

O que torna a transição brasileira um caso exemplar de transição por transação ou negociação é o fato de que as elites políticas deram início ao processo de transição enquanto ainda estavam no poder. Essa iniciativa em geral ocorre diante do aumento dos custos para a manutenção de um regime autoritário. Com a intenção de negociar uma posição política confortável no novo regime, iniciam o processo com a intenção de manter o controle do mesmo em suas mãos. Para tanto, negociam com a oposição e apoiadores, aproveitandose da posição de poder que ainda têm em mãos. $\mathrm{O}$ fato de estarem à frente do estado no início do processo permite fixar limites da atuação de todos os autores envolvidos e, ao mesmo tempo, introduzir medidas liberalizantes. Isto é, introduziram alguns direitos que [...] garantem a proteção de atos ilícitos cometidos pelo Estado e ao mesmo tempo mantiveram o poder de veto sobre a ação de outros atores [...] (MARQUES, 2018, p. 23).

A própria Constituição da Federal de 1988 é produto das incongruências que definem o processo de redemocratização. Nela encontra-se condensada uma tradição histórica de "enfrentamento" dos conflitos pela legislação. Com isso não queremos questionar o ato de legislar, mas a forma como se legisla no Brasil: criam-se leis descoladas da realidade. Longe de serem inoperantes, as leis brasileiras são mal operadas. Trata-se de um complexo "[...] sistema de estratagemas e complicações burocráticas usado pelo Estado e por indivíduos para ofuscar problemas, neutralizar oponentes, garantir a impunidade e, acima de tudo, legalizar o ilegal" (HOLSTON, 2013, p. 44). Como assevera Raymundo Faoro (2007, p. 173),

Há, neste caso, a desarmonia entre a situação de fato - a constituição social - e as normas constitucionais, tidas por 
prematuras, na versão conhecida da menoridade do povo. Com o tempo, pelo desenvolvimento de condições reais, a constituição viria a ser aplicada, reduzida, no presente, a um manual educativo. [...]. Enquanto esse dia não chega, os detentores do poder mandam e desmandam, também eles envoltos na confortável - confortável para eles - esperança do futuro, seja do país grande potência, do país rico ou do país educado.

O reconhecimento dado pela Constituição de 1988 aos direitos individuais e coletivos (tal como preconizado em seu art. $5^{\circ}$ ) foi meramente protocolar. A Constituição "cidadã" cumpriu formalmente com a recomendação da comunidade internacional (referimo-nos à agenda democrática, a serviço das classes abastadas), mas não assegurou o usufruto daqueles direitos, pois não criou as condições para o desmonte da matriz das disparidades sociais do Brasil. A Constituição é garantista em direitos e, ao mesmo tempo, absolutamente evasiva sobre as agências reguladoras que deveriam garantir esses direitos. Sustenta-se, de um lado, uma cidadania tutelada e regulada e, de outro, dispositivos de controle e regulação emancipados e desestabilizados. ${ }^{3}$ Esses contrastes trazem consigo violências que, se antes obtinham a chancela do Estado Ditatorial, no regime democrático, passaram a ser reproduzidas pela sociedade civil (LIMA, 1999).

Essas violências possuem graus distintos dissociados por códigos de conduta que operam em função do sistema de privilégios próprio da estrutura de desigualdades vigente no Brasil. Por exemplo: por que no senso comum a concentração exacerbada de riqueza não é vista como algo tão violento quanto um homicídio? Cientes da complexidade dessa questão, ousamos afirmar que a dificuldade em associar o tipo de violência expressa no primeiro caso àquela que se apreende no segundo está relacionada com o tipo de uso que é feito da categoria "civilidade". Para o

3 Vide o art. 144 da Constituição Federal, que se restringe a reproduzir lobbies e contra-lobbies de monopólios de práticas de policiamento, confundindo-as com mandatos de polícia. 
senso comum o homicídio é um ato muito menos civilizado que o acúmulo desproporcional de riquezas. Os usos da civilidade se diferenciam não apenas em relação à natureza das situações em questão, mas, fundamentalmente, em relação a outras categorias sociais, como cor, renda, sexo, etc. Em outros termos, a civilidade não opera distanciada dos atributos físicos, sociais e econômicos individuais.

O emprego da civilidade não se dá de forma unilateral. Se por um lado essa categoria é mobilizada para sustentar privilégios, por outro, ela também o é para reivindicar direitos. Essas "reações" tendem a ser sublevações de discursos ocultos conservados em espaços de dissidência marginal. Segundo James Scott (200o, p. 21, tradução nossa),4

[...] Cada grupo subordinado produz, a partir do seu sofrimento, um discurso oculto que representa uma crítica ao poder pelas costas do dominador. O poderoso, por outro lado, também elabora um discurso oculto em que as práticas e demandas de seu poder são articuladas e não podem ser expressas abertamente. Comparando o discurso oculto dos oprimidos com o dos poderosos, e ambos com o discurso público das relações de poder, aderimos a uma maneira fundamentalmente distinta de entender a resistência ao poder.

A percepção de uma dimensão infrapolítica serve sem prejuízos à compreensão dos conflitos que perpassam o convívio urbano no Brasil. Sobre ela são constituídas as técnicas de subversão das condições estruturais de opressão. Mas essa percepção dos discursos ocultos não retira ou reduz o caráter estratégico dos discursos públicos sobre as dinâmicas de emancipação política. Do contrário,

4 “[...] Cada grupo subordinado produce, a partir de su sufrimiento, un discurso oculto que representa una crítica del poder a espaldas del dominador. El poderoso, por su lado, también elabora un discurso oculto donde se articulan las prácticas y las exigencias de su poder que no se pueden expresar abiertamente. Comparando el discurso oculto de los débiles con el de los poderosos, y ambos con el discurso público de las relaciones de poder, accedemos a una manera fundamentalmente distinta de entender la resistencia ante el poder." (SCOTT, 2000, p. 21). 
[...] quanto maior a desigualdade de poder entre o dominante e o dominado e mais arbitrariamente o poder é exercido, o discurso público do dominado adquirirá uma forma mais estereotipada e ritualística. Em outras palavras, quanto mais ameaçador for o poder, mais espessa será a máscara. [...] As exigências teatrais geralmente impostas em situações de dominação produzem um discurso público que corresponde muito à aparência que o grupo dominante quer dar (SCOTT, 200o, p. 26-27, tradução nossa). ${ }^{5}$

$\mathrm{Na}$ cena urbana brasileira as ideologias que demarcam objetivamente posições de superioridade e de inferioridade podem ser apreendidas nos procedimentos que regulam os contatos públicos entre distintos segmentos sociais. Tomemos por exemplo o caso maceioense: há pouco mais de cinco anos, a Prefeitura de Maceió desenvolve na orla marítima da cidade um projeto de "reordenamento" que tem por finalidade "[...] a melhoria do convívio, da segurança e o combate à informalidade na região" (CARVALHO, 2018, p. o2).

Os bairros da orla marítima de Maceió são reconhecidos pelos nativos como "bairros da elite". Neles residem as classes média e médiaalta locais. Ponta Verde destaca-se entre os demais por um tipo de requinte que lhe é próprio: prédios e residências de alto padrão, luxuosas galerias, amplo comércio restrito às condições econômicas dos residentes. Trata-se de um bairro com um elevado padrão de vida.

O trecho de praia que leva o mesmo nome do bairro, cartão postal da Cidade Sorriso, reúne pessoas de todas as partes do Brasil e do mundo. Também reúne pessoas de outras partes da cidade, notadamente, das periferias. Para os frequentadores mais assíduos (e observadores), os

5 “[...] cuanto más grande sea la desigualdad de poder entre los dominantes y los dominados y cuanto más arbitrariamente se ejerza el poder, el discurso público de los dominados adquirirá una forma más estereotipada y ritualista. En otras palabras, cuanto más amenazante sea el poder, más gruesa será la máscara. [...] Las exigencias teatrales que generalmente se imponen en las situaciones de dominación producen un discurso público que corresponde mucho a la apariencia que el grupo dominante quiere dar." (SCOTT, 2000, p. 26-27). 
espaços de atuação dos agentes que concorrem pelos usos da praia de Ponta Verde parecem ser muito bem definidos: na faixa de areia situada entre as famosas barracas Lopana e Kanoa repousam os residentes do bairro, "a elite", branca e abastada. Já os trechos que se estendem do Lopana à estrutura do antigo clube Alagoinhas e do Kanoa à feirinha do artesanato (que demarca o limite entre os bairros de Ponta Verde e de Pajuçara) são reservados para os "farofeiros", categoria nativa mobilizada na definição (senão estigmatização) dos moradores de bairros periféricos que acessam a orla. ${ }^{6}$ Não há entre os residentes das periferias quem se atreva a ultrapassar esses limites simbólicos. Aqueles que o fazem se submetem aos olhares constrangedores ou incorrem o risco de serem contestados (como no caso que descrevemos nas primeiras linhas deste artigo).

A atuação da guarda municipal e da polícia militar nessa região da cidade, enquanto instrumento de mediação dos contatos públicos inscrito naquilo que é entendido por "reordenamento" pelos gestores municipais, se restringe aos espaços de atuação dos sujeitos periféricos. Não à toa que guardas e policiais se posicionam nas extremidades da orla de Ponta Verde, onde, como dissemos anteriormente, se reúne o público periférico, principalmente os jovens (pobres e negros em sua grande maioria). Revistas, intervenções e apreensões constantes denunciam um propósito que não condiz com o discurso público de "melhoria do convívio".

Nas cidades brasileiras os contatos públicos são historicamente mediados por governabilidades que privilegiam a conduta das elites. As narrativas sobre segurança pública ilustram com precisão esse dilema, vide os desentendimentos que demarcam a gestão das políticas de

${ }^{6}$ A origem do termo "farofeiro" está no fato de muitos moradores de periferia levarem para a praia toda sorte de petiscos e refeições, sendo a "farofa" um item indispensável. Para uma ampla definição da categoria "farofeiro" ver Araújo e Andrade (2011). 
segurança no país. A (des)continuidade dessas ações reflete uma série de disputas por categorias morais, por projetos de sociedade e por modos de produção da política. Nas periferias esses embates são extremamente violentos dada a influência de fatores diversos, dentre os quais figuram no contexto atual a expansão dos mercados formais e informais (notadamente, o mercado imobiliário) e as novas configurações das redes criminosas (BRETAS, 2019; NASCIMENTO, 2019; PAIVA e FREITAS, 2016; FELTRAN, 2014).

Entendemos que parte das narrativas e codificações sobre o direito à cidade é construída nos lugares onde se originam os discursos e as práticas políticas voltadas ao reconhecimento desse direito. Nesse sentido, as periferias se constituem enquanto locus "privilegiado" de construção do debate em torno dos usos e contra-usos dos espaços urbanos. Com base nesse pressuposto tomamos a perspectiva das periferias como objeto de análise a fim de compreendermos as condições que orientam o posicionamento e a mobilização nos conflitos que marcam o convívio urbano no Brasil. Antes, contudo, devemos nos situar em relação aos autores das narrativas que traduzem as dinâmicas que nos interessam neste estudo. Na seguinte seção descrevemos os métodos empregados nas pesquisas que fundamentam o presente trabalho e tecemos breves reflexões em torno da relação entre nosso lugar de fala e o lugar de fala dos agentes pesquisados.

\section{Periferias, lugar de fala e os trabalhos de campo}

O reconhecimento do saber antropológico se constituiu a partir dos países centrais durante o período colonial. A despeito das problematizações em torno da figura do antropólogo europeu que estudava nativos, descrevia suas sociedades e interpretava suas culturas, entendemos que as assimetrias basilares entre o sujeito do conhecimento 
e o sujeito-objeto pesquisado continuam a permear os trabalhos da disciplina. Esse é um tipo de problema que não se apreende nesta pesquisa. Nossa "condição periférica"7 não apenas nos assegurou o acesso a espaços, práticas e discursos pouco tangíveis àqueles que partem de uma realidade outra, como também nos permitiu experimentar sensações não disponíveis publicamente e extremamente significativas para a análise e a intervenção.

A opção pelo uso da primeira pessoa do plural no curso da escrita deste artigo não é meramente formal. Ela reflete um sentido de pertencimento que serve à compreensão da relação entre o nosso lugar de fala e dos indivíduos pesquisados, sentido esse que não dispensa ou encobre o tipo de distanciamento analítico preconizado pelo método científico no âmbito dos estudos realizados nas ciências humanas (CHIZZOTTI, 2018).

Quanto aos termos empregados na caracterização do objeto de estudo da presente pesquisa, reconhecemos os riscos de reduzir a pluralidade que hoje define as comunidades periféricas a um conjunto homogêneo (FELTRAN, 2014). Nietzsche já nos alertava para essa questão:

\begin{abstract}
Todo conceito nasce por igualação do não-igual. Assim como é certo que nunca uma folha é inteiramente igual a uma outra, é certo que o conceito de folha é formado por arbitrário abandono destas diferenças individuais, por um esquecer-se do que é distintivo, e desperta então a representação, como se na natureza além das folhas houvesse algo que fosse "folha", uma espécie de folha primordial, segundo a qual todas as folhas fossem tecidas, desenhadas, recortadas, coloridas, frisadas, pintadas, mas por mãos inábeis, de tal modo que nenhum exemplar tivesse saído correto e fidedigno como cópia fiel da forma primordial (NIETZSCHE, 200o, p. 56 apud BIONDI, 2018, p. 17).
\end{abstract}

7 Ciente dos riscos, e com o devido constrangimento, assumo a primeira pessoa do singular para me descrever como um jovem (pesquisador), negro, morador de periferia. 
Nesse sentido, considerando que "a palavra e o conceito não são, em princípio, 'verdadeiros”' (VELHO, 2007, p. 159 apud BIONDI, 2018, p. 17), sentimo-nos autorizados a falar de "periferias" e de "sujeitos periféricos", como uma estratégia discursiva utilizada para referirmo-nos a toda essa diversidade sintonizada em uma mesma "condição".

As constatações que se seguem são produto de três diferentes estudos realizados entre os anos de 2015 e 2017 em comunidades periféricas das cidades de Maceió (Grota do Arroz e Grota do Rafael), de Belo Horizonte (Cabana do Pai Tomás e Morro do Papagaio) e do Rio de Janeiro (Morro dos Macacos). Tratam-se de trabalhos de campo desenvolvidos com a finalidade de compreender distintas sociabilidades, seus eixos estruturantes e seus desdobramentos na dinâmica da vida daqueles que ali residem.

$\mathrm{O}$ acesso às comunidades, nos casos de $\mathrm{BH}$ e do Rio, foi viabilizado por moradores com quem estabelecemos contatos prévios e explicitamos objetivos da pesquisa. No caso de Maceió, o ingresso nas grotas foi facilitado por amigos e conhecidos, igualmente residentes daqueles locais. Entre as técnicas utilizadas nos estudos, todas de ordem qualitativa, destacam-se os relatos etnográficos e as entrevistas semiestruturadas.

Com relação às falas revisitadas para este artigo em particular, apesar de traduzirem as percepções de distintos indivíduos situados em diferentes contextos (referimo-nos às diferentes cidades nas quais se inserem as comunidades estudadas), nos dedicamos às regularidades inscritas nos usos de categorias mobilizadas na descrição de um dilema que nos mostrou ser igualmente regular, qual seja, o das lutas pelo efetivo exercício de cidadanias urbanas.

Na seguinte seção propomos uma reflexão sobre as condições que precedem a insurgência, sob a pretensão de se fazer valer uma cidadania pautada no acesso aos espaços públicos, na emancipação política e na 
garantia de direitos contestados pelos arroubos de privilégios do centro, dito “civilizado”.

\section{A (im)posição das periferias nas lutas pela cidadania urbana}

Nos últimos vinte anos, as cidades brasileiras se veem assoladas por um processo triplamente negativo: a dissolução, a fragmentação e a privatização dos espaços (VÉRAS, 2018). Esses processos engendram-se e se reforçam mutuamente contribuindo para o desaparecimento do “espaço público” na medida em que acentuam a marginalização e a desigualdade, reduzindo a capacidade de governança urbana e a integração cidadã.

Os conflitos que decorrem do contato entre os atores que compõem a cena urbana brasileira denota a operação de dinâmicas distintas, por vezes contraditórias, por vezes complementares. Nos termos de Ramos e Pimentel (2015, p. 141), observa-se nos espaços centraisperiféricos

[...] uma determinada legitimidade, emanada do espaço periférico-central, ou seja, é o estado político incorporando em suas práticas o simbólico popular, e o simbólico popular incorporando em suas práticas o estado político como forma de se fazer presente e ser reconhecido. É o discurso urbano buscando institucionalizar o real da cidade; buscando ordenar as relações que acontecem no fluxo que é a cidade, e que não pode ser abarcado pela burocracia estatal. [...] o popular é representado no centro mais em um espaço pré-determinado, pré-estabelecido. Já na periferia há materialidades funcionando como centrais, pois passam por um processo de institucionalização por parte do poder público que dota determinado espaço de legitimidade, reconhecendo-o politicamente [...].

No agenciamento de direitos, verificam-se a princípio duas dinâmicas em operação: partindo do centro, a estigmatização reificada pelo projeto político histórico de perpetuação das disparidades sociais; e 
da periferia, a ressignificação dos marcos de atuação, expressa na contestação das ingerências e injustiças perpetradas contra os menos favorecidos (FELTRAN, 2010). Em outros termos, se o centro, de um lado, manipula códigos de civilidade para sustentar cidadanias diferenciadas que desmembram direitos alheios, estigmatizando aqueles que atentam contra os privilégios que decorrem dessa "estrutura de contrastes", de outro, a periferia ressignifica esses mesmos códigos para a contestar as cadeias restritivas, articulando recursos materiais e políticos à disposição a fim de que lhe seja garantido o acesso a direitos outrora cerceados.

Nas periferias, contudo, esse "estado político", que precede a mobilização, se depara com diversos obstáculos. O primeiro deles é, fundamentalmente, a própria composição das comunidades periféricas, heterogênea, ${ }^{8}$ que em última instância reflete em disposições diferenciadas isoladas em relação a qualquer tipo de mobilização que alce a pretensão de garantir o pleno exercício efetivo de uma cidadania urbana. Sujeitos plurais reservam discursos igualmente diversificados e uma vez dispersos desconhecem (e assim reduzem) a potencialidade de qualquer “ação coletiva”, tal como se pode apreender da fala destacada a seguir:

\begin{abstract}
É todo mundo pedindo uma coisa diferente. [...] um quer rua calçada, outro quer creche, outro quer transporte público, e aí no final das contas fica esse tanto de demanda e ninguém decide nada, e não se consegue nada. Nem a gente que dirige a associação tem poder pra direcionar a atenção do povo, porque a gente não pode decidir pela comunidade. A demanda tem que ser formalizada com uma petição descrevendo o problema [...] e a assinatura do pessoal pra confirmar que é um problema coletivo. Mas tem certas coisas que não interessam para uns e que são mais interessantes para outros. Uns assinam, outros não [...]. Essa falta de consciência prejudica muito a gente. $\mathrm{O}$ povo não entende que a mudança vem de pouquinho em pouquinho, sabe? Querem tudo de uma vez e acabam ficando sem nada (Presidente de associação
\end{abstract}

\footnotetext{
${ }^{8}$ Existem códigos de civilidade que são operados pela periferia para a própria periferia. Tratam-se de estados contínuos de emulação dos critérios de diferenciação que podem ou não estar relacionados com a garantia de privilégios (FELTRAN, 2014).
} 
comunitária, Grota do Rafael, Maceió, em entrevista concedida ao autor).

Por vezes as possibilidades de mobilização dos distintos interesses individuais em impulsos coletivos de reivindicação se vêem frustradas pelos sistemas informais que se constituem e operam dentro das próprias periferias. São as (novas) dinâmicas do crime, que intercalam as ações de facções e do mercado. Tratam-se de técnicas de policiamento e regulação operadas pelas redes criminosas que se estabelecem nas periferias, e que, em muitas das vezes, atuam como franquias chanceladas pelo Estado, em uma espécie de terceirização informal e ilegal.

Nas disputas territoriais de facções estão inscritas lógicas de mercado: a expansão dos territórios serve ao estabelecimento de hegemonias e monopólios que, direta ou indiretamente, se estendem sobre a população e, ao mesmo tempo, implicam em quedas acentuadas nas taxas de criminalidade. Essa mesma população parece gradualmente conscientizar-se dessas dinâmicas, incorporando-as em maior ou menor medida, a exemplo do que se verifica no seguinte trecho:

\footnotetext{
Nós somos reféns. [...] é vivendo na mira do revólver, da metralhadora, agindo 'de acordo' com eles. Ninguém se atreve a pedir um serviço diferente, ninguém se atreve a denunciar pra a polícia porque eles descobrem. Eles descobrem e vem aqui tirar satisfação. E quando eu digo 'tirar satisfação' é meter bala mesmo. [...] E eles tem apoio da polícia, eles tem apoio da política. [...] a favela é um mercado e é um mercado que dá dinheiro (Morador da comunidade Cabana do Pai Tomaz, Belo Horizonte, em entrevista concedida ao autor).
}

Se essas dinâmicas encerram "chances" de ação coletiva (dirimindo conflitos, já que retiram da equação um de seus polos), por outro ângulo acirram conflitos de ordens diversas. Nos termos de Gabriel Feltran (2014, p. 508), 
[...] Quando nem a lei, nem o que é considerado certo podem mediar a relação entre cortes populacionais e seus modos progressivamente autônomos de conceberem a si e aos outros, é o dinheiro que aparece como único modo objetivo de mediar suas relações. Ao invés de politizar a questão social ou os pilares da vida comunitária, portanto, parece-me que o híbrido dessas equações de mediação - o dinheiro - tem, ao contrário, elevado em muito a intensidade do conflito latente entre as formas de vida que, hoje, se elaboram nos cortes biopolíticos que esquadrinham as cidades brasileiras.

Se o Estado não se faz minimamente presente (ou o faz para cooptar informalmente as lógicas que operam nos espaços de periferia), o crime passa a ditar os termos do exercício da cidadania, municiando os cidadãos. A fala de um professor da rede pública municipal atuante no Morro dos Macacos, cidade do Rio de Janeiro, é signatária desse processo:

O que é que você acha que é mais chamativo para um menino de 15 anos, nascido e criado no morro, sem qualquer perspectiva de vida? A 'ideia' de que é melhor ele estudar, pra crescer e ser um homem de bem, com um bom emprego, com uma família ou o revólver pra ele descer pra o asfalto e tocar o terror? [...] Pra ganhar dinheiro fácil levando droga de um morro para o outro? Comprar o tênis que ele queria, comprar o celular que ele queria? Parecer com quem ele queria parecer? O crime 'abre essas portas'. E em muitas das vezes você até percebe que não é por querer. [...] eu falo porque conheço muito bem os meus alunos. Sei das necessidades que cada um aqui passam. [...] E enquanto o governo deixa de montar escolas, o tráfico levanta verdadeiras faculdades.

A insegurança urbana é um dos principais corrosivos dos usos do espaço público e, portanto, da construção da cidadania citadina. Muito embora o conflito seja um elemento constituinte do convívio urbano, no Brasil, as cidades têm assumido a face da inevitabilidade da violência. E este medo da cidade está especialmente ligado ao uso do espaço público. Nesse processo, surge a "agorafobia urbana", ou seja, o medo dos espaços públicos (VÉRAS, 2018).

O valor da educação e do respeito à propriedade se constrói com um lastro ideológico que mascara as hierarquias e as desigualdades de 
acesso a recursos e direitos, de cidadania. Existe, portanto uma relação entre a civilidade hegemônica e a impossibilidade irrestrita do exercício da cidadania, como se este demandasse a adoção de padrões de civilidade.

Nos circuitos de constrangimento social (sobre os quais se encontram dispostos os discursos ocultos de opressão e de percepção da injustiça, as lógicas paralelas e concorrentes do "mercado do crime" e as distintas, por vezes inoperantes, demandas de acesso a direitos), a despeito das contradições que a violência reserva em si mesma, residem potencialidades difusas na "incivilidade". Esse idioma público de profunda indignação enseja a expansão da cidadania democrática, desestabilizando o regime diferenciado, sem substituí-lo. É aquilo que Holston (2013, p. 329) denomina como "incivilidade reflexiva".

\begin{abstract}
Sabe o que é que a gente faz? Primeiro a gente implica, depois a gente começa a filmar. Faz eles passarem vergonha. [...] Que quem disse que 'favelado' não pode ir pra praia? [...] tem muito preconceito ali dentro e eles começam a por para fora. Em tudo que põem pra fora, a gente expande. Mostra pra todo mundo. [...] Você já viu esses casos de assédio e coisas assim no que deu. É porque tudo isso acontece escondido. Porque quando fica público pesa pra o lado deles. E se a gente não consegue contestar à altura, a gente faz isso para não ficar por baixo. E ainda tem a satisfação de ver eles sendo vaiados, deles se envergonhando e indo embora, porque não aguentam ser contestados (Morador do Morro dos Macacos, Rio de Janeiro, em entrevista concedida ao autor).
\end{abstract}

Essa insurgência tende a provocar fortes reações contrárias por parte dos grupos sociais que se beneficiam do modelo de perpetuação das desigualdades sociais, que lançam mão do entrincheiramento na tentativa de restabelecer o antigo regime de diferenciação. $\mathrm{O}$ episódio relatado a seguir demonstra uma forma sutil de operação dessa lógica:

Eu nem sei mais quantas vezes a polícia chegou mandando acabar com a roda [de Rap] porque ligaram dizendo que era coisa de maconheiro, de maloqueiro, que a gente estava depredando a praça ou coisa do tipo. [...] Eu só vim pra dar o 
meu salve, pra deixar a minha mensagem, pra questionar justamente esse tipo de coisa que me incomoda. [...] e isso aqui é espaço público e eu estou querendo que me vejam mesmo, mas eles não sabem ou não querem ver (Morador da Grota do Arroz, Maceió, em entrevista concedida ao autor).

Tem-se difundido o discurso de que aquilo que se diz democrático também se apresente como violento. Existe certa conveniência em conceber a democracia como representativa de pacificidade. Mas se o regime é erguido sobre bases fraturadas, cada vez mais é possível que ele passe a se ancorar em processos violentos. Dessa forma, a própria instituição da democracia se dá por processos violentos e não por conquistas cidadãs. Violenta-se como recurso à civilidade produzindo ações incivilizadas, vistas muitas das vezes como amparo da ordem ou requisitos da abertura de espaços democráticos.

\section{Considerações finais}

O convívio nos centros urbanos brasileiros é cada vez mais democrático, mas também mais violento. Essas violências operam historicamente, física e simbolicamente, sobre contextos situados, norteando os agenciamentos urbanos pelos quais os espaços são produzidos como lugares de conflitos, condutas em formas surdas ou abertas de resistência. Nas periferias, os conflitos com a lei e o poder refletem transversalidades e ressonâncias mais amplas. Esses conflitos e pontos de atrito não se tratam apenas de disputas sobre os próprios modos de produção e administração dos ordenamentos urbanos, exercícios de governabilidade que afetam os modos de ser e de viver. São fundamentalmente signos de resistências e protestos contra os excessos das "forças da ordem".

A insurgência se realiza a partir de circuitos de constrangimento social. Apesar de todas as contradições que incidem sobre o processo de 
articulação técnica (em parte, como reflexo direto das estruturas de disparidades que operam no Brasil), as estratégias de insurgência operam cumulativamente na forma de discursos ocultos, assumindo, finalmente, a forma pública por meio de "incivilidades" que a princípio denotam um fluxo de códigos de conduta manipulados em prol da manutenção das cadeias opressivas; atos que podem, ou não, surtir efeitos (positivos ou negativos) sobre essas mesmas cadeias. Quando se vive na periferia, o exercício máximo da cidadania é fazer tomar ciência de que o arroubo de privilégios impede a existência de outros sujeitos no espaço público.

Nessa perspectiva, o espaço público emerge não apenas como um cenário de ação, mas também de comunicação, expressando um enredo de relacionamentos mediados pela mudança de interesses e propósitos em torno de uma realidade objetiva do mundo comum. Estes relacionamentos unem e separam indivíduos e grupos de distintos segmentos. No curso desse processo de interação expressa-se o conteúdo político da vida pública, a forma como as questões de interesse comum são debatidas e definidas e a forma como a cidadania é exercida nas cidades. Essa concepção tem influenciado o (recente) debate sobre o espaço público e suas transformações associadas tanto às consequências da modernidade na vida pública e privada quanto às mudanças ocorridas na relação estado-sociedade.

\section{REFERÊNCIAS}

ARAÚJO, A; ANDRADE, M. O. Excursões populares e turísticas: um enfoque sobre quase grupos e práticas de lazer na praia. Ponto Urbe [Online], $\quad$ v. 2011. 9, Disponível em: <http://journals.openedition.org/pontourbe/36o>. Acesso em: 25 maio 2019 .

BIONDI, Karina. Junto e misturado: uma etnografia do PCC. São Paulo: Terceiro Nome, 2018. 
BRETAS, Marcos Luiz. A guerra das ruas: povo e polícia na cidade do Rio de Janeiro. Rio de Janeiro: Gramma, 2019.

CARVALHO, Roberta Bastos de. "Aqui tem cultura”: bárbaros, procurem seus lugare. Maceió, 2018. Trabalho não publicado.

CHIZZOTTI, Antonio. Pesquisa em ciências humanas e sociais. São Paulo: Cortez Editora, 2018.

FAORO, Raymundo. Assembleia constituinte: a legitimidade recuperada. In: FAORO, Raymundo. A república inacabada. São Paulo: Globo, 2007.

FELTRAN, Gabriel. Periferias, direito e diferença: notas de uma etnografia urbana. Revista de Antropologia, v. 53, n. 2, p. 565-610, 2010.

O valor dos pobres: A aposta no dinheiro como mediação para o conflito social contemporâneo. Caderno CRH, v. 27, n. 72, p. 495-512, 2014 .

HOLSTON, James. Cidadania insurgente. Disjunções da democracia e da modernidade no Brasil. São Paulo: Companhia das Letras, 2013.

LEITE, Rogério Proença. Contra-usos da cidade: lugares e espaço público na experiência urbana contemporânea. Campinas: Editora Unicamp/UFS, 2004.

LIMA, Roberto Kant de. Polícia, injustiça e sociedade no Brasil: uma abordagem comparativa dos modelos de administração de conflito no espaço público. Revista de Sociologia e Política, v. 1, n. 13, p. 23-38, 1999.

MARQUES, Teresa. A transição negociada no Brasil e o jogo político em torno da construção da agenda dos direitos humanos. In. SALATA, A.; MARQUES, T.; PONTIN, F (orgs.). 30 anos de democracia no Brasil: avanços e contradições. Porto Alegre: EDIPUCRS, 2018.

NASCIMENTO, Fillipi Lúcio. A McDonaldização do narcotráfico e seus desdobramentos no estado de Alagoas. Revista Transgressões, v. 7, n. 2, 2019 (no prelo).

PAIVA, L. F.; FREITAS, G. J. Ecos da violência nas margens de uma sociedade democrática: o caso da periferia de Fortaleza. Sociedade e Cultura, v. 1, p. 115-128, 2016. 
RAMOS, T. R.; PIMENTEL, R. M. A relação centro-periferia na discursividade da cidade. RUA, v. 17, n. 2, p. 128-144, 2015.

SCOTT, James. Los dominados y el arte de la resistencia. Trad. Jorge Aguilar Mora. México: Era Ediciones, 2000.

VÉRAS, Maura Pardini Bicudo. Desigualdades urbanas: algum marco conceitual? In: (org.). Desigualdades urbanas, segregação, alteridade e tensões em cidades brasileiras. Jundiaí, SP: Paco Editorial, 2018, p. 19-32. 